Claves. Revista de Historia, Vol. 2, $\mathrm{N}^{\mathrm{O}} 3$

Montevideo, Julio-Diciembre 2016

(pp. 225-250) ISSN 2393-6584

\title{
El encuentro con lo no-europeo en el proceso de definición de Europa
}

\author{
Jean-Frédéric Schaub \\ EHESS-Mondes Américains \\ Silvia Sebastiani \\ EHESS-Centre des recherches historiques
}

Recibido: 10/05/2016

Aceptado: 15/06/2016

Resumen: Este artículo recorre las trayectorias históricas de formación de la europeidad, poniendo el foco en la tensión entre lo europeo y lo no europeo como clave interpretativa a fin de dar cuenta de una reformulación identitaria eminentemente cambiante y aún hoy inacabada. Adoptar ese enfoque supone revisar la historia de Europa, de modo de poner a distancia los prejuicios etnocéntricos de carácter europeo que han dominado en el trabajo de los historiadores. En lugar de darle la espalda a la historia europea, actitud que solo contribuiría a que esos prejuicios sigan prevaleciendo, los autores proponen recorrer otro camino, que exponen a través del estudio de hechos históricos concretos acaecidos principalmente en la época Moderna: el "descubrimiento" del Nuevo Mundo, las conquistas, la progresiva secularización, la forja de categorías raciales, el dominio de la información sobre otros pueblos. En ese marco destaca la Ilustración, verdadero laboratorio para la definición de la europeidad (y de sus contradicciones), a través de las ideas de civilización y de universalidad de los derechos del hombre. Aplastar y conocer; dominar y describir; eliminar e inventariar: esos son los pasos de las andanzas de Europa a escala global.

Palabras clave: Identidad - Europeo - No Europeo

The encounter with the non-European in the shaping of Europe

Abstract: This article traces the historical trajectories of the shaping of Europeanness, by focusing on the tension between the European and the nonEuropean. It accounts for a continuously changing reformulation of European 
identity, which is far from being achieved even nowadays. This approach requires to revisit the history of Europe by taking a sharp distance from the Eurocentric prejudices which have all too often dominated historians' work. Instead of turning their back to European history - an attitude that would only contribute to reinforce these prejudices - the authors propose to follow a different path, which they expose through the study of concrete historical facts occurring in the early modern period: the "discovery" of America, the conquests, the processes of secularization, the forging of racial categories, the control of information about other peoples. Within this context, Enlightenment becomes a laboratory for the shaping of Europeanness (including its contradictions), through the idea of civilization and of the universality of the rights of man. Taming and knowing, dominating and describing, destroying and inventing: these are Europe's routes of wandering at global scale.

Key words: Identity - European - non-European

El etnocentrismo propio de las universidades de corte y tradición occidentales, estén donde estén situadas, tiene por nombre eurocentrismo. Hace ya mucho (1978) que la crítica del orientalismo redunda en denuncia de un occidente tenido por imperialista e incapaz de describir y apreciar la complejidad y los sabores específicos de culturas no europeas. Criticar el eurocentrismo parece tanto más necesario en cuanto que la producción literaria, política y, por ende, filosófica y de ciencias sociales nacida en Europa no solo habla de sí misma, sino también de lo que le es ajeno. En otras palabras, a lo largo de los cinco o seis últimos siglos, uno de los rasgos singulares de la dinámica cultural europea ha sido su capacidad para describir sus “otros”, eso sí deformándolos, interpretándolos, reduciéndolos a una identidad o a una alteridad, tan erróneas la una como la otra, según los casos. Lo imperdonable de los europeos no es tanto que hayan conquistado tierras y borrado pueblos o sistemas políticos de la faz de la tierra, porque eso también lo hicieron la expansión china en extremo oriente, la epopeya islámica medieval, el triunfo continental de los mongoles, etc. Tampoco ha sido propio de los europeos el haber acompañado sus triunfos político-militares por doquier con discursos auto-legitimadores: todos los poderes conquistadores hicieron lo mismo, romanos, bizantinos, árabes, otomanos, persas, mogoles, aztecas, etcétera. Lo imperdonable es que los europeos se hayan tomado la 
molestia de hacer correr, a la par que ríos de sangre, ríos de tinta para describir a sus conquistados, para interpretar su mundo, para llenar museos con sus productos culturales y obras de arte, etc. El resentimiento que expresa el pensamiento sedicente de-colonial no resulta de la brutalidad europea, sino de la curiosidad europea. Es decir que, pasada la etapa de la descolonización, quedan las humanidades y las ciencias sociales forjadas en las universidades de tradición europea para describir cuantas sociedades no-europeas se presenten. El resentimiento también se nutre de las contradicciones clamorosas entre la defensa de los universalismos del cristianismo y luego, de los Derechos del Hombre y la superioridad que los europeos se han otorgado a sí mismos dentro de una concepción jerárquica de la humanidad.

Después de la etapa de la crítica del "orientalismo", entre las estrategias propuestas para escapar del eurocentrismo contamos con la voluntad de enfocar la investigación sobre procesos de profundo alcance en los que los europeos no tomaron más que poca o ninguna parte. Entre las sociedades asiáticas, esa meta puede contar con la existencia de fuentes en todas aquellas lenguas que quedaron plasmadas por escrituras nativas. Han florecido, en las últimas décadas, trabajos espléndidos tanto sobre los grandes imperios asiáticos como sobre la circulación de personas y mercancías en los mares y océanos desde el oriente de África hasta el sur y el este de Asia. Con aquellas sociedades que no dejaron más que pocas o ninguna huellas escritas indígenas anteriores a la colonización europea no se puede ofrecer nada parecido, ni de lejos. Hasta aquí, con brocha gorda, la situación presente de la historiografía internacional, al menos como la ven los autores de estas reflexiones. Nuestro artículo parte de una idea que no podría ser más simple: la mejor forma de deshacerse de los prejuicios etnocéntricos de carácter europeo consiste en conocer bien la historia de Europa. El darle la espalda a Europa es el método más seguro para que esos prejuicios sigan dominando en el trabajo de los historiadores.

\section{La palabra Europa y su idea}

Para empezar tenemos que enfrentar un problema clásico y frecuente para la historia conceptual e intelectual: hasta qué punto un concepto pudo ser operativo, en parte al menos, antes que la palabra que lo refiere haya estado en uso en la sociedad. En el caso que nos ocupa, no dudemos que las sociedades políticas de muchos países de Europa, de Lisboa a Cracovia, de Edimburgo a Budapest, de Palermo a Estocolmo, 
produjeron discursos positivos sobre lo que unía sus realidades frente a otros universos, mucho antes de que el concepto de Europa como noción cultural, política y por ende jurídica estuviera afianzado en la lengua de la filosofía y de la política. Dicho de otro modo, la conciencia colectiva de que lo que unía a los europeos superaba a lo que los dividía según distintas geografías en el transcurso del tiempo, antes de que se manifestara el uso corriente de la palabra Europa.

Europa como conciencia propia es sustitutiva de la Cristiandad medieval y moderna. Es fruto de un proceso secularizador que afectó las sociedades europeas en el transcurso de los períodos moderno y contemporáneo. Importa notar de inmediato que no existe ningún consenso entre historiadores sobre la cronología y el ritmo de dicho proceso. Unos identifican elementos de emancipación de las sociedades políticas en relación con las iglesias desde conflictos bajo-medievales entre el altar y el trono, otros insisten sobre el peso de la autoridad eclesiástica y espiritual hasta después de las revoluciones liberales. Sea como fuere, importa resaltar el hecho incontrovertible de que los europeos de la Alta Época Moderna, siglos XVI-XVII, fueron marcados por estallidos de violencia religiosa devastadores (guerras de religión, Inquisición, caza de brujas), así como por un nuevo paisaje espiritual (fin de la unidad romana, emergencia de un pensamiento escéptico y libertino, primera "revolución científica"), y por una expansión colonial llevada a una escala desconocida, mucho más amplia de lo que fuera la memoria de la Roma imperial y de las Cruzadas en la cuenca oriental del Mediterráneo.

En cuanto los historiadores intentan definir Europa como territorio y como civilización se topan de inmediato con problemas insalvables. Somos herederos de imágenes del pasado que actúan en nuestro pensamiento a la manera de mitos. Grecia, sede de la ciudadanía política y cuna de la cultura filosófica; Roma, parangón de la ley y del orden; Cristiandad medieval universal, que dio a luz a una Europa de catedrales y universidades; Renacimiento y revoluciones científicas; las Luces, frente universal del pensamiento crítico; triunfo del crecimiento económico en la estela de las dos primeras revoluciones industriales: sobre esos pilares están edificadas no sólo nuestras memorias, sino también nuestras historiografías. ${ }^{1}$ Una mirada amplia sobre lo que podríamos llamar el perímetro adecuado de cualquier estudio sobre el pasado

\footnotetext{
${ }^{1}$ VERGA, Marcello, Storie d'Europa, secoli XVIII-XXI, Roma, Carocci, 2004.
} 
de Europa produce un cierto desánimo, si lo que se pretende es establecer un marco geográfico a priori en el cual una sociedad europea reconocible hubiera desarrollado sus caracteres originales.

\section{¿Europa sin límites?}

Para empezar, permanece abierta la cuestión insoluble de la frontera oriental de Europa. ${ }^{2}$ Del proceso histórico de formación del imperio ruso, ¿qué elementos merecerían ser incorporados en una historia de Europa y qué elementos tendrían que quedar fuera? Sea cual fuere la contestación a esta pregunta, dos respuestas parecen descartadas: todo y nada. Dicho de otra forma, así como realidades pertenecientes a Asia Central y más aún al extremo Oriente ruso y soviético (por ser espacios coloniales) pueden quedar legítimamente fuera del cuadro europeo, así otras realidades como la religión ortodoxa y sus redes de conventos, la participación rusa en las guerras europeas contra el imperio otomano, las artes de Pushkin a Grossman o de Chaikovski a Shostakóvich, o la penetración del leninismo en Europa occidental hacen que no sea de recibo la exclusión del mundo ruso fuera del ámbito europeo.

Si bien la lucha contra el imperio otomano acerca la Rusia imperial a otros países europeos, la pertenencia a Europa de zonas que estuvieron incorporadas al imperio otomano merece un serio debate. Aquí uno puede prescindir del papel simbólico de Grecia como cuna de nuestra racionalidad y sin embargo mantenida bajo el yugo turco. ¿En nombre de qué lógica deberíamos excluir sociedades cristianas, o parcialmente convertidas al islam, de la península de los Balcanes de nuestra Europa, durante los siglos de su pertenencia al imperio otomano? Y si aceptáramos esta forma de pensar, en nombre de una definición estrechamente cristiana de la realidad histórica de Europa, entonces buena parte de la historia medieval de España y Sicilia tendría que salir de nuestro concepto de historia de Europa. ¿Quién se atrevería hoy a excluir el Califato de Córdoba de la historia europea? Existen serios motivos para incorporar a la historia de Europa a aquellas zonas que estuvieron integradas a los imperios islámicos. ${ }^{3}$ No sólo el hecho de que muchas de esas zonas estuvieron posteriormente dominadas por sistemas políticos

2 WOLFF, Larry, Inventing Eastern Europe: The Map of Civilization on the Mind of the Enlightenment, Palo Alto, Stanford University Press, 1994.

3 DAKHLIA, Jocelyne; VINCENT, Bernard (ed.), Les musulmans dans l'histoire de l'Europe, vol. I, Une intégration invisible, Paris, Albin Michel, 2011. 
cristianos lo justifica. Desde la realidad compleja del islam bajo autoridad cristiana en la España medieval, hasta la convivencia de señores ortodoxos con administradores otomanos en tierras de habla rumana, pasando por la permeabilidad cultural entre las tres religiones del Libro: todo apunta a que europeidad y cristiandad no se adecuen en la elaboración del trabajo historiográfico. $\mathrm{Y}$ esto sin contar con la presencia del judaísmo rabínico en toda Europa que, a diferencia del islam, no descansaba sobre la existencia de una realidad institucional y territorial judía.

En todo caso, no hay más remedio que admitir dentro del relato de Europa lugares e incluso culturas que en algún momento fueron interpretados como periferias externas de un centro más o menos heredero del desvanecido imperio romano. El ejemplo magiar se nos antoja particularmente llamativo. Esa "puerta" de la Cristiandad romana (a Gate según la expresión estudiada por Nora Berend), después de la coronación del rey Esteban, se convierte en parangón de europeidad. 4 No olvidemos, en efecto, que la cristiandad europea no sólo tuvo que resistir los embates del islam conquistador, no sólo tuvo que definir políticas adecuadas en relación con la persistencia del judaísmo, sino que tuvo que completar la obra de evangelización de poblaciones y reyes paganos. Llama la atención el hecho de que la conversión de los lituanos (comenzada en 1386) tuviera lugar durante las primeras navegaciones hacia el archipiélago de Canarias. Los historiadores deben llamar la atención sobre la contemporaneidad factual de procesos que nuestras memorias sitúan erróneamente en períodos distintos.

\section{Identidad y alteridades}

Sabiendo que estamos enfrentando un tema conceptualmente abierto por no decir movedizo, vale la pena insistir en un par de paradojas esclarecedoras. En primer lugar, la sociología histórica muestra una y otra vez hasta qué punto la dinámica de diásporas alimenta el proceso de génesis de identidades colectivas. Todas las entidades políticas europeas de la Alta Época Moderna eran sistemas compuestos, agregaciones de territorios dispares con diversidades jurídicas, lingüísticas y culturales internas. Los abanicos de esas pluralidades tendieron a cerrarse a medida

\footnotetext{
4 BEREND, Nora, At the gate of Christendom: Jews, Muslims, and "pagans" in medieval Hungary, c. 1000 - c. 130o, Cambridge-Nueva York, Cambridge University Press, 2001.
} 
que sujetos de cada país, por muy diversas que fueran sus características, tuvieron que edificar juntos colonias en nombre de su rey o república en África, Asia o América. Si bien las "naciones" hispanas en América, la vasca, la montañesa, la andaluza, etcétera siguieron marcando diferencias, el contraste con los nativos del Nuevo Mundo y con los esclavos africanos aceleró la toma de conciencia de su unidad. Lo mismo se produjo, por ejemplo, con los distintos componentes del Reino Unido en la India durante el siglo XVIII.5 En segundo lugar, al coincidir con la madurez del proceso secularizador, la toma de conciencia de una identidad europea, en rigor, es contemporánea del triunfo de las ideologías nacionales. Es más, la conciencia europea se hace explícita cuando en América las colonias asumen su independencia, denunciando el antiguo sistema imperial europeo, y cuando cada Estado nacional europeo aspira a crear un imperio colonial de nuevo tipo. ${ }^{6} \mathrm{El}$ siglo $\mathrm{XX}$, en su primera mitad, ofrece un panorama sorprendente: Europa se autodefine como tutora de aquellas sociedades que todavía no habían entrado en el proceso de las revoluciones industriales, mientras las rivalidades nacionales intra-europeas producen el peor desastre registrado en la historia de la humanidad.

Volviendo al período alto-moderno, parodiando la célebre fórmula, podría decirse que Europa es un territorio dividido por una misma religión. A la medieval división entre cristianismo romano y cristianismo griego, la Época Moderna añade la fractura de la Iglesia romana. Aquí lo más importante es recordar que los actores de la época establecieron relaciones entre la alteridad encontrada en mundos externos y la fractura interna de la unidad cristiana. Mientras hombres de Europa viajaban por tierras y mares repletos de sorpresas y de fenómenos desconocidos, su mundo veía alejarse cada vez más el espejismo de una unidad en la Iglesia de Cristo. Los europeos enfrentaron de forma más o menos simultánea tres regímenes de alteridad: el paganismo en África, Asia y América, la infidelidad del imperio otomano y del Mediterráneo islámico, y las herejías cristinas (papismo versus protestantismo).

La ruptura entre el período medieval de Europa y la Época Alta Moderna estuvo pues marcada por tres acontecimientos fundadores: la toma de la capital del antiguo imperio romano de Oriente por los otomanos en 1453, el descubrimiento

5 COLLEY, Linda, Britons: Forging the Nation, 1707-1837, New Haven, Yale University Press, 1992. ${ }^{6}$ WESSELING, Henk, Europa's kolonial eeuw. De kolonial rijken in de negentiende eeuw, 1815-1919, Amsterdam, Bert Bakker, 2003. 
americano y la ruptura impuesta por Lutero. A estos tres episodios conviene añadir su coincidencia con la invención de la imprenta y sus consecuencias fundamentales para la difusión de los conocimientos sobre las realidades internas y exteriores a Europa. Esos fenómenos responden exactamente al análisis anterior. Efectivamente, buena parte de la literatura ensayística o épica del siglo XVI edificó un juego de espejos y correspondencias entre esas variaciones sobre la alteridad. Otelo, el mercader de Venecia y Calibán; Montaigne disertando sobre los brasileños traídos a Ruan, sobre los criminales de las guerras de religión y sobre nuestros antepasados de la Antigüedad: he aquí dos de los ejemplos más famosos de esa cultura capaz de ubicar la alteridad no solo entre un nosotros y los otros, sino más bien dentro del nosotros a la luz de los otros. El cambio de paradigma en la definición de la barbarie puede servir de buen síntoma del surgimiento renacentista de auténticas novedades.7

Efectivamente, si uno se sitúa a finales del siglo XVI y principios de la centuria siguiente se encuentra con un paisaje nuevo. Durante toda la Edad Media el modelo centro versus periferia sirvió para diferenciar la vida civilizada de la vida bárbara. Sea el esquema de Herodoto en su Historia, oponiendo el mundo de las ciudades políticas y realidades distintas (imperio persa, nomadismo escita, modelo egipcio), o la teoría climática debida a Hipócrates (tierras templadas para el desarrollo de la vida cívica, contra zonas áridas o gélidas): el mapa mental de la barbarie descansaba en una representación de tipo centro versus periferia. Si ahora contemplamos el problema al final de un período marcado por el enfrentamiento con el turco hasta en la cuenca del Danubio, los "Descubrimientos" y las guerras de religión nos encontramos con un mapa mental totalmente desdibujado.

En primer lugar, los europeos descubren en América, con la desnudez y la falta de concupiscencia de los indígenas del Caribe, una humanidad contemporánea de Adán: antes de la expulsión del Jardín del Edén. Pero al mismo tiempo, las mismas crónicas denostaban a aquellas poblaciones dadas al canibalismo. De tal manera que las mismas expediciones devolvieron a Europa la imagen del indígena como "noble salvaje” y como pueblo satánico. ${ }^{8}$ En segundo lugar, siguiendo las propias crónicas

\footnotetext{
7 SCHAUB, Jean-Frédéric, "«Nous, les barbares" : expansion européenne et découverte de la fragilité intérieure", Patrick BOUCHERON (ed.), Histoire du monde au XVe siècle, Paris, Fayard, 2009, pp. 813-829.

8 GLIOZZI, Giuliano, Adamo e il Nuovo Mondo. La nascita dell'antropologia come ideologia coloniale dalle genealogie bibliche alle teorie razziali (1500-1700), Florencia, La Nuova Italia, 1977.
} 
ibéricas e italianas de las primeras décadas del siglo XVI, y más todavía el uso propagandístico que de ellas hicieron los países protestantes contras los ibéricos, no existe figura más bárbara que la del conquistador capaz de las peores crueldades contra indígenas indefensos, como los tercios hispanos en tierras holandesas. Así es como, en el marco de las guerras de religión, la imagen del europeo armado en sus conquistas de ultramar se convierte en retrato del peor bárbaro. En tercer lugar, en la estela de los fenómenos de colonización interna y de persecución ya presentes en Europa desde por lo menos el siglo XI, poblaciones europeas ubicadas en los márgenes de la sociedad o del espacio político fueron vistas como bárbaras, aunque vecinas. Piénsese en los casos de los irlandeses con su idioma y sus costumbres menospreciados, de los vascos con sus aquelarres, de los bretones con sus supersticiones, de los moriscos con su apego clandestino al islam, y otros tantos. En cuarto lugar, durante la Alta Época Moderna la impronta del pensamiento renacentista no se limitó a redescubrir y traducir a los clásicos. Mientras la cultura sofisticada pagana y cristiana de la Antigüedad marcaba las pautas de la política, de la filosofía y del derecho, la referencia a los pasados bárbaros de cada corona se hacía cada vez más presente. El deseo de emancipar las dinastías del siglo XVI de la soberanía teórica del Sacro Emperador y de la Santa Sede llevó a los propagandistas de las cortes reales a realzar la memoria del pasado bárbaro de cada sociedad. Trátese de los pueblos prerromanos o de los invasores germánicos protagonistas de las invasiones que acabaron con el imperio romano de occidente, esos antepasados se convirtieron en fuente de legitimidad para la autoridad de los príncipes de la Alta Época Moderna. Basta pensar en el goticismo castellano, en la exaltación del pasado "Briton" de Inglaterra, en el éxito de las nuevas ediciones de la Germania de Tácito, para entender hasta qué punto el mundo de las letras creó entonces una imagen muy positiva de los pueblos bárbaros de su propio pasado. En quinto y último lugar, el desdoblamiento territorial y político del fenómeno de la barbarie desembocó en una auténtica revolución filosófica: el descubrimiento de la presencia de lo bárbaro en la propia mente de cada sujeto. La ironía de Cervantes, el furor de los reyes y cortesanos perdidos de Shakespeare, el escepticismo de Montaigne: he aquí las tres expresiones más clamorosas de ese descubrimiento interno, tan importante como fueron los descubrimientos del mismo siglo. En el corazón de una Europa de señores cultos y ciudades complejas, de ordenamientos políticos sofisticados, de bellas artes desarrolladas y príncipes espléndidos, acecha lo bárbaro, no sólo en los márgenes de 
la sociedad, sino también en el corazón de cada sujeto, por muy controlado que esté.

\section{¿Europa definida por sus conquistas?}

Ese tránsito es de suma importancia para entender hasta qué punto el espectáculo de la alteridad externa modificó la mirada sobre sí mismos de los europeos. Frente a la amenaza de desaparición entre uno mismo y lo otro, los europeos forjaron todo tipo de respuestas. La unidad religiosa no era operativa, desde la separación entre la Iglesia de Roma y la ortodoxia griega a la ruptura entre el catolicismo y los protestantismos, sin contar con la persistencia del judaísmo y restos del islam ibérico. Además, la expansión demostró hasta qué punto los europeos en contexto colonial, sea como colonos, soldados, cautivos, casados con mujeres nativas, etcétera, podían acercarse a los pueblos de África, Asia y América hasta fundirse en ellos. Ni unidos en casa, ni sólidos fuera de ella: la gran lección para los europeos de la Modernidad temprana fue el descubrimiento de su propia debilidad. La angustia provocada tanto en ultramar como entre los lectores de relatos de viajes y crónicas, entre los sacerdotes y sus misiones semi-fracasadas, entre los jueces y letrados de las sociedades de Europa favoreció todo tipo de contra medidas ideológicas para afianzar la imagen de sí. ${ }^{9}$ La más clamorosa y la que tuvo el mayor impacto a largo plazo fue sin duda la forja de categorías raciales no tanto para describir la alteridad sino para crearla.

El descubrimiento de mundos ubicados más allá de las columnas de Hércules, como indica el frontispicio del Novum Organum del filósofo y político inglés Francis Bacon, cambió para siempre los fundamentos del pensamiento científico de los europeos. No sólo llegaron noticias de climas, paisajes, plantas y animales de los que no se disponía de ninguna descripción, sino que se impuso plantear la unidad y la pluralidad del ser humano en términos nuevos. La disputa entre las interpretaciones monogenista y poligenista de la diversidad humana nace en ese preciso momento, creando una nueva tensión entre el dogma de la palabra revelada y el raciocinio científico contemporáneo de la expansión europea. Más que una tensión se trata de una auténtica brecha que nunca volvería a cerrarse, ya que va de la mano de un proceso -eso sí, no lineal ni de igual empuje en toda Europa- de secularización de las creencias.

9 HAZARD, Paul, La crise de la conscience européenne, Paris, Boivin, 1935. 
El 1492 hispánico había marcado un deseo de unidad cristiana en el preciso momento en que la sociedad española se colocó en la vanguardia del contacto con un mundo sin límites. Sin embargo, las huestes ibéricas, con sus misioneros y mercaderes, forjaban una ideología de retaguardia para enfrentar desafíos nuevos. La expulsión de los judíos, la conversión forzada de los musulmanes fueron el contexto paradójico de las audacias de Colón. ${ }^{10}$ Una ideología que veía en los rancios árboles genealógicos de la hidalguía castellana el nec plus ultra de la excelencia, fue la herramienta de la que dispuso la gran empresa colonial española. Poco menos de dos siglos más tarde fue en Francia en donde algo parecido se produjo. En menos de un año, en 1684-1685, en el apogeo del poder de Luis XIV, François Bernier publica la primera descripción de la humanidad dividida según "razas", el rey promulga el Code Noir, primer código de la condición esclava y, revocando el famoso Edicto de Nantes, impone a los protestantes la conversión o el exilio. Así a finales del siglo XVII, una potencia en auge, como habían sido Castilla y Aragón al final del siglo XV, enfrenta la empresa colonial con una mentalidad intransigente y dogmática. Mientras tanto, el dominio de las empresas coloniales había crecido a costa del exclusivismo ibérico, sin que disminuyera el desconcierto. Es más, los europeos ya no solo tenían que gestionar la relación entre sociedades de origen colonial europea con pueblos nativos, sino que tenían que vigilar el monstruo demográfico, cuando no ético, que habían creado deportando cientos de miles de personas de África hacia América. ${ }^{11}$

Del modelo ibérico al modelo francés, que tanto influyeron en las sociedades británica y holandesa, los europeos forjaron categorías raciales para consolidar su integridad y sistema de dominación, tanto en las colonias como en la propia Europa. La limpieza de sangre ibérica y la ideología nobiliaria establecieron reglas destinadas a frenar la integración de familias indeseadas (conversos, labradores o artesanos no nobles, advenedizos, extranjeros) en los círculos de poder locales y generales. Se trataba de un sistema de exclusión racial provocado por procesos de integración. En las tierras coloniales, reglas semejantes fueron desarrolladas para limitar el acceso de mestizos de todo tipo a los estatutos sociales y privilegios de las familias europeas sin mezcla étnica. Por ende, en sociedades marcadas tanto en ultramar como en las metrópolis por la explotación del sistema de plantaciones y minas esclavistas, el

10 PROSPERI, Adriano, Il seme dell'intolleranza. Ebrei, eretici, selvaggi, Granada 1492, Roma-Bari, Laterza, 2011.

${ }^{11}$ BOULLE, Pierre H., Race et esclavage dans la France de l'Ancien Régime, Paris, Perrin, 2007. 
pensamiento racial fue movilizado tanto para justificar -en contexto cristiano- la esclavitud, como para mantener a raya a los libertos deseosos de fundirse en la sociedad de los libres. Así es como el pensamiento racial fue movilizado para consolidar una entidad propiamente europea en el proceso de expansión global de los europeos en los cinco continentes.

De ese desconcierto, el último capítulo de los viajes de Gulliver es buen testimonio. Al regresar a Inglaterra, el doctor Lemuel Gulliver ya no puede verse la cara en el espejo por la vergüenza que le produce la comparación con pueblos de calidad y cultura superiores. La jerarquía de las sociedades ya no podía estar marcada sólo por la reinterpretación de los textos sagrados. Sin duda, los europeos mantenían abierta la memoria de las excelencias paganas de Grecia y de Roma. Ahora tenían que enfrentarse con las excelencias de la China, por no dar más que el ejemplo que se convirtió en el mayor desafío a la autoestima europea. Desde la obra seminal del jesuita Matteo Ricci a finales del siglo XVI e inicios del XVII, hasta la "querella de los ritos chinos" en el Imperio Medio, China hasta por la larga duración de su propia historia no cuadraba en el esquema judeocristiano. Pero, por vía dialéctica, la imagen de superioridad que a sí mismas se confieren las sociedades europeas se consolida por el hecho de que los europeos actúan como exploradores y como historiadores de sociedades externas. Así es como va siendo superada la "crisis de la conciencia europea" a pesar de que la unidad ideada de Europa parecía alejarse para siempre, y a pesar de que otras sociedades lejanas parecían superar a las europeas. Quedan dos herencias fundamentales de la primera etapa colonial. La primera es la producción de una nueva jerarquía de los pueblos basada en caracteres raciales, siendo los europeos dignos de todo elogio. La segunda es la toma de conciencia de que son letrados europeos quienes escriben y describen la diversidad del mundo, como científicos y como historiadores, en un sistema de relaciones no simétricas entre Europa y el resto del mundo. Esas dos herencias fundamentales de los primeros siglos de expansión colonial son recogidas por la Ilustración mediante conceptos, cuya pretendida universalidad puede ser entendida como la manifestación del sentido europeo de la propia superioridad intelectual. Las Luces forjaron la idea -hasta hace poco vivaz en la historiografía- de que Europa es la civilización por antonomasia: en ese sentido los 
ilustrados armaron un gran laboratorio para la definición de la europeidad.12

\section{Europa y el privilegio de la historia}

En el corazón de ese laboratorio está un modo nuevo de escribir la historia. Más allá de las profundas diferencias entre contextos nacionales y entre los ilustrados, existen rasgos comunes. La crítica racionalista empuja la historia fuera de los modelos clásicos y cristianos en un proceso secularizador. La perspectiva geográfica se ensancha y los temas se hacen más diversos, con especial inquietud hacia los usos y costumbres de los pueblos, más que hacia reyes y príncipes. Con el desarrollo de un pensamiento comparatista, se abren caminos nuevos, conceptos claves para armar el discurso historiográfico, dejando de lado la mera sucesión cronológica. La historia, como laboratorio de la "ciencia del hombre", se centra en leyes parecidas a las leyes de la física. Parte de tres supuestos: el hombre pertenece al sistema de la naturaleza y es clasificado con los demás animales; su naturaleza es uniforme, lo que significa que enfrentando contextos parecidos reacciona de forma parecida; evoluciona y mejora a lo largo del tiempo, según el proceso histórico.

La historia es fundamental para el pensamiento ilustrado, tanto que David Hume define su época como una "edad histórica" ("historical age"). Libros de historia se convierten en auténticos best-sellers, con varias ediciones, traducciones y reseñas. Por primera vez, los historiadores consiguen vivir de su trabajo. La historia desempeña pues un papel inédito, respetando criterios de objetividad y seriedad en el análisis de las fuentes, al tiempo que deleita a lectores y lectoras. Así es como temas hasta entonces jamás incorporados en los relatos históricos hacen acto de presencia, trátese de las costumbres, de la familia, de la vida privada, de los sentimientos. ${ }^{13}$

Los relatos de viajes y libros de geografía refuerzan las nuevas historias ilustradas en una Europa cada vez más comprometida con la recolección, la elaboración y la difusión de informaciones detalladas sobre sus territorios y sus colonias, imprescindibles para cobrar impuestos, sacar partido a las riquezas

\footnotetext{
12 VERGA, Marcello, ob. cit., p. 9 ('L'Europa è anzitutto un'idea, un valore, una civiltà, anzi un'idea di civiltà"); CHABOD, Federico, Storia dellïdea di Europa, Roma-Bari, Laterza, 1989.

${ }_{13}$ Sobre el mundo británico: PHILLIPS, Mark Salber, Society and Sentiment. Genres of Historical Writing in Britain, 1740-1820, Princeton, Princeton University Press, 2000; SHER, Richard B., The Enlightenment and the Book. Scottish Authors and their Publishers in Eighteenth-Century Britain, Irlanda y América, Chicago-Londres, University of Chicago Press, 2006.
} 
naturales y mantener ejércitos a una escala cada vez más global. Las circunnavegaciones, el descubrimiento del Pacífico, de Siberia, del estrecho de Bering, la profundización de los conocimientos sobre América, así como nuevas informaciones lingüísticas, se corresponden de forma cada vez más estrecha con viajes dentro de Europa, en el campo atrasado, como las Tierras Altas (Highlands) de Escocia, los alrededores de Nápoles o la Rusia de la servidumbre. Vaya un ejemplo: el viajero y filósofo Georg Forster, compañero del capitán Cook en su segunda vuelta al mundo, que describió las costumbres de los “yellow-brown skinned” de las islas del Pacífico en su A Voyage Round the World (1777), también viajó dentro de Europa. Escribió un cuaderno de viaje sobre usos y costumbres de los pueblos que visitó y acabó publicando un relato sobre los hábitos de la gente en las riberas del Rin. En su trabajo, introdujo las categorías y los términos empleados para representar lo exótico en sus descripciones como "salvaje interno" o "Indias de acá” (según la expresión acuñada por los jesuitas). ${ }^{14}$ Las exploraciones, patrocinadas por instituciones políticas, fueran comerciales o científicas, movilizan cada vez más científicos, geógrafos y cartógrafos en Europa y fuera de ella. Observaciones, informaciones, datos geográficos y antropológicos, investigaciones eruditas, frutos de correlaciones de fuerza asimétricas facilitaron la acumulación de conocimientos necesarios para desarrollar un análisis comparativo de las sociedades humanas. La publicación de los grandes relatos de viaje (De Bry en el mundo germánico, Raleigh en Inglaterra, Thévenot en Francia) hizo posible acumular y comparar informaciones.

El proceso de acumulación de saberes convierte a Europa en centro neurálgico a escala global para la difusión de informaciones. Desde 1702, Londres dispone de un diario (Francia solo tendrá el suyo al final del siglo), en los años 1730 tiene seis, y en los años 1780 existen unos sesenta en Gran-Bretaña. ${ }^{15}$ La prensa crea una opinión pública y nuevos modos de entender la nación. El imperativo creciente de informar a un público de lectores y lectoras es central en la Ilustración, cuyo ejemplo más evidente sigue siendo la Encyclopédie de D’Alembert y Diderot. Los ilustrados eran conscientes de este proceso y lo reconocían como propio de Europa. El papel

\footnotetext{
14 FORSTER, Georg, Ansichten vom Niederrhein, von Brabant, Flandern, Holland, England und Frankreich, im April, Mai und Junius 179o, (1791), ed. G. Steiner, Berlin, 1958; Id., "Tagebücher", in Georg Forsters Werke, Berlin, 1973, vol. 12.

15 COLLEY, Linda, ob. cit.; BAYLY, Christopher A., Empire and Information. Intelligence Gathering and Social Communication in India, 1780 1870, Cambridge, Cambridge University Press, 1997.
} 
emancipador de la imprenta y de la prensa no fue mejor explicado que en el Tableau historique des progrès de l'esprit humain de Condorcet.

La búsqueda de noticias responde también a objetivos políticos. Resulta imprescindible en lo interno, da cuenta un monopolio administrativo sobre su territorio y sus pueblos. La capacidad de sacar partido de informaciones y difundirlas depende de infraestructuras y relaciones - posta, caminos, navegación interna. Como es sabido, las figuras claves del triunfo británico no son tanto héroes militares (Marlborough, West o Nelson), sino sus "transcriptores, copistas y archiveros" que cambiaron las estructuras fiscales y militares del imperio, y cuyo número creció en cantidades sin precedente. ${ }^{16}$ Ellos fueron quienes proporcionaron los datos más precisos sobre los recursos del imperio, fueron más eficaces para recoger los impuestos, mejoraron el control social.

\section{El comparatismo como matriz de la europeidad}

La masa de noticias acumulada en los centros europeos permite una nueva mirada antropológica, basada en la comparación sistemática entre las sociedades humanas. ${ }^{17}$ Ese pensamiento resulta de la confluencia de diversos géneros literarios que favorecen su amplia difusión entre las élites europeas. Las Lettres persanes (1721) de Montesquieu abren esa tradición, mediante una mirada doble: los persas aparecen como observadores externos de las costumbres francesas y al mismo tiempo, su experiencia francesa los hace externos a los asuntos persas y, en consecuencia, críticos sobre ellos. El comparatismo es lo que permite relativizar, explicar, criticar: al decir que todo juicio se refiere a quien lo emite y que toda cultura es coherente en sí misma, Rica y Usbek abren camino hacia el relativismo cultural. ${ }^{18}$ Ese relativismo es el fundamento de la gran obra de la madurez de Montesquieu, L'esprit des lois (1748), en la cual el autor asume el papel del hombre de ciencia que analiza y compara costumbres, usos, formas de gobierno de los pueblos del mundo,

\footnotetext{
${ }^{16}$ BREWER, John, The Sinews of Power: War, Money, and the English State, 1688-1783, Nueva York, Knopf, 1989, p. xvi.

17 LATOUR, Bruno, "Ces réseaux que la raison ignore: laboratoires, bibliothèques, collections", M. BARATIN; C. JACOB (ed.), Le Pouvoir des bibliothèques. Le Pouvoir des livres en Occident, Paris, Albin Michel, 1996, pp. 23-46.

18 WOLFF, Larry, "Discovering Cultural Perspective. The Intellectual History of Anthropological Thought in the Age of Enlightenment", Larry WOLFF; Marco CIPOLLONI (ed.), The Anthropology of the Enlightenment, Stanford, Stanford University Press, 2007, pp. 3-32.
} 
en función de sus situaciones propias. Mediante la comparación, Europa se ve unificada como zona de clima templado y cuya geografía está marcada por la división en entidades políticas pequeñas, como garantía de libertad e interdependencia.

Si Mœurs sur les sauvages amériquains comparées aux mœurs des premier temps (1724) del jesuita Joseph-François Lafitau presentan una explicación clásica del problema de la diversidad religiosa, como consecuencia de la expulsión del paraíso y de la corrupción humana, demuestran su capacidad de ordenar una cantidad impresionante de datos de manera sintética. Comparando, punto por punto, las creencias y usos de pueblos distantes en el espacio y en el tiempo, la obra abre camino para una ciencia universal del hombre. Lafitau defiende que los pueblos nativos de América del Norte descienden de los antiguos griegos. Proporciona de forma sistemática una tal cantidad de paralelismos que resulta imposible negar las similitudes, y que la teoría de la filiación genética puede quedar de lado. ${ }^{19}$ Mediante el doble plano espacio-temporal de la América salvaje y de la Grecia Antigua, el pensamiento enfrenta la doble alteridad: "el pasado es como la distancia" habría dicho Buffon, medio siglo después de Lafitau, en un texto tan materialista como Les époques de la nature, que ofrece un riguroso paralelo entre historia civil e historia natural, la primera volcada en la búsqueda de la épocas de las revoluciones humanas, la segunda sobre las diferentes edades de la naturaleza. En ambos casos, la comparación aparece como el único modo de formar un nuevo pensamiento. Para hacer posible el conocimiento de novedades tenía que existir necesariamente una relación con lo viejo y conocido. América y sus habitantes eran constantemente vistos en relación con Europa, África y Asia, mientras la comparación permitía medir las diferencias entre los distintos mundos, en el sentido de un reforzamiento de la europeidad. ${ }^{20}$

La explicación de las diferencias entre los pueblos está subrayada en la comparación y entra en un nuevo cuadro analítico, el del progreso por etapas, desarrollado en particular entre los ilustrados escoceses. La historia de la humanidad

19 MEEK, Ronald L., Social Science and Ignoble Savage, Cambridge, Cambridge University Press, 1976, pp. 57-64; DUCHET, Michèle, Anthropologie et histoire au siècle des Lumières (1971), Postface de Claude Blanckaert, Paris, Albin Michel, 1995, p. 15.

${ }^{20}$ BUFFON, G.L.L., Des époques de la nature (1778), en Euvres, ed. S. Schmitt, Paris, 2007, pp. 11931195; HOQUET, Thierry, "La nouveauté du Nouveau Monde du point de vue de l'histoire naturelle", G. ABBATTISTA; R. MINUTI (ed.), Le problème de l'altérité dans la culture européenne. Anthropologie, politique et religion aux XVIIIe et XIXe siècles, Nápoles, Bibliopolis, 2006, pp. 129-158. 
está descrita como una sucesión de estadios -caza, cría, agricultura, y comercio- y la Europa del siglo XVIII se ve en el ápice del proceso. Así es como Europa se convierte en fruto de un proceso histórico, representa la sociedad civil en tanto que se opone a sociedades rústicas y salvajes como las de los amerindios, o bárbaras como las de los tártaros y chinos. La palabra clave para entender ese proceso es "civilización", término jurídico que describía la conversión de una causa criminal en causa civil, y que adquiere en la segunda mitad del siglo XVIII un significado nuevo. Entonces empieza a significar el estadio avanzado de la cultura y de la sociedad y, al mismo tiempo, el tránsito por el que llegan la cultura y la sociedad a ese resultado. ${ }^{21} \mathrm{El}$ neologismo "civilización" se sitúa en el corazón de la nueva historia filosófica y natural de la sociedad humana de Voltaire a Raynal, Diderot y Condorcet, hasta Thomas Paine, Georg Foster y Wilhelm Humboldt, Adam Smith o William Robertson. Es el concepto estructurador de la Ilustración. Permite designar el progreso de las instituciones y de las relaciones sociales, incluso las de género, de una sociedad comercial moderna en vías de cambio rápido. Más ampliamente, el proceso civilizador se impone como proceso de crecimiento de la sociabilidad en tanto que se opone al salvajismo y a la barbarie, en los que la premura de las necesidades materiales obstaculizaba un alto nivel de cooperación e intercambios. El pensar sobre ese proceso impone una revisión radical de los relatos heredados sobre los orígenes de la sociedad humana. ${ }^{22}$

\section{El giro antropológico de la Ilustración}

Ese giro desvincula al hombre de su dependencia con la divinidad y lo inserta en el mundo animal, del cual al mismo tiempo se diferencia por su capacidad para crear y plasmar su propia historia. El homo se define sobre todo por el adjetivo sapiens, según el Systema Naturae de Linneo (1735). Mientras la racionalidad es sólo uno de sus atributos, el conocimiento es común a las cuatro variedades humanas, la

\footnotetext{
${ }^{21}$ FEBVRE, Lucien, "Civilisation: évolution d'un mot et d'un groupe d'idées" (1930), in Pour une histoire à part entière, Paris, SEVPEN, 1962, pp. 481-528; STAROBINSKI, Jean, "Le mot civilisation", en Le remède dans le mal: Critique et légitimation de l'artifice à l'âge des Lumières, Paris, Gallimard, 1989, pp. 11-59. Más recientemente: LILTI, Antoine, "L'impossible histoire globale. Parcours de la "civilisation", Antoine LILTI; Sabina LORIGA; Jean-Frédéric SCHAUB; Silvia SEBASTIANI (ed.), L'expérience historiographique. Autour de Jacques Revel, Paris, Editions de l'EHESS (Enquêtes n. 12), 2016, pp. 181-200.

${ }^{22}$ PAGDEN, Anthony, “The 'Defence of Civilization' in Eighteenth-Century Social Theory”, History of the Human Sciences, 1, 1988, pp. 33-45.
} 
roja, la blanca, la negra y la amarilla. Al clasificar a los humanos en su complejo "sistema de la naturaleza", Linneo ya no los define como imagen de Dios. A su vez, Buffon rechaza ese sistema de clasificación y busca sin embargo preservar para la humanidad una situación privilegiada. La coloca en una naturaleza en movimiento, ofreciendo por primera vez una auténtica historia natural (Histoire naturelle générale et particulière, 1749-1789). En su perspectiva, el hombre evoluciona de una situación muy cercana al mundo animal hasta una completa realización de su humanidad, situación propia de los europeos. En la base del desarrollo está el principio de perfectibilidad, o capacidad de mejorar sus propias facultades con el tiempo y por tanto, la condición propia. Aunque pertenece al mundo natural, el hombre de Buffon, como el de Montesquieu, nunca aparece en estado de naturaleza, sino siempre en sociedad.

La posibilidad de concebir al hombre como parte del mundo animal abre, sin embargo, el camino hacia un discurso que, si bien critica de forma definitiva el cuadro bíblico, conlleva sus propias contradicciones. Un ejemplo llamativo es la teoría poligenista defendida por Voltaire. En el Essai sur les mœurs (1756), la perspectiva universal resulta del descentramiento desde Europa hasta China del inicio de la historia, entendida en todo caso como historia de la civilización. Voltaire parte de China porque se trataba, según él, de la civilización más antigua y la primera en progresar. Así rompe por completo con la historia universal providencialista y centrada en Europa de Bossuet. Del modelo de la perfección se pasa al de la perfectibilidad. ${ }^{23}$ Pero lo que interesa aquí es sobre todo el hecho que China es fundamental para entender la especificidad de la civilización europea, la única que habiendo protagonizado la revolución científica no se detuvo en el camino del progreso, aunque hubiera partido de un punto débil. Por el contrario, los chinos, cuya historia era mucho más antigua como muestran las cronologías, y que llegaron a ser civilizados mucho antes que los europeos, de repente cortaron su propio camino. Después de haber descentrado la atención sobre otras civilizaciones, Voltaire vuelve al "nosotros": el final del Essai habla de un "nosotros" frente al "ellos", los orientales y los demás pueblos no europeos. De ese modo, la historia de la civilización global

\footnotetext{
${ }_{23}$ KAEGI, Werner, "Voltaire e la disgregazione della concezione cristiana della storia", en Meditazioni storiche, Bari, Laterza, 1960, pp. 216-238. LILTI, Antoine, "La civilisation est-elle européenne ? Ecrire l'histoire de l'Europe au XVIIIIe siècle", A. LILTI; Céline SPECTOR (ed.), Penser à l'Europe au 18 siècle, Oxford, Voltaire Fondation, 2014, pp. 139-166.
} 
aparecía como el camino de la razón, en el que los distintos pueblos habrían participado de forma desigual.

El preámbulo del Essai, añadido en 1769, reunía los distintos rasgos poligenéticos dispersos en la primera edición y aclaraba el significado del proceso histórico. La nueva introducción no histórica del Essai sur les mours, mediante una "Philosophie de l'histoire", ordenaba en una única perspectiva la detención del progreso chino, el fallido desarrollo de los amerindios y la servidumbre de los negros. En esa óptica, los chinos aparecen como raza por sí misma, por el color de su piel, la forma de su nariz, ojos, orejas pero también por su inteligencia. Los negros, además de la diferencia física evidente, se distinguían por una clara inferioridad intelectual y una pobre capacidad de concentración. Con su credo poligenista colocado al principio de su historia universal, Voltaire confiere una base natural a la diferencia de los procesos históricos. Por tanto, los europeos se diferencian como especie.

Siguiendo un camino paralelo al de Voltaire, pero rechazando claramente el poligenismo, el historiador escocés William Robertson empieza con una historia nacional (History of Scotland, 1759) y acaba con las historias de América (1777) y de la India (1791-1792). En ellas el camino histórico se presenta como un proceso civilizador, por el cual las sociedades avanzan siguiendo estadios, haciéndose cada vez más complejas en cuanto a hábitos, leyes y formas de gobierno. En el tiempo histórico, lo "salvaje" se desarrolla en "civil", la independencia y la precariedad originarias dejan paso a la libertad y a la seguridad de la era del comercio. Así, el hombre realiza su plena humanidad. El motor de esa historia global es la propiedad privada, con la desigualdad y la complejidad que conlleva.

En 1769 Robertson había publicado su History of the Reign of the Emperor Charles $V$, en la cual se preguntaba sobre la formación de la sociedad civil en Europa y sobre lo que caracteriza y distingue a la Europa moderna de la Antigüedad, así como de todos los demás pueblos en la Tierra. Según su interpretación, fue en la época de Carlos V cuando los Estados europeos comenzaron a estar vinculados unos con otros con cadenas que conformaron un nuevo y único "great political system", que duró hasta su tiempo:

"Los grandes acontecimientos que tuvieron lugar entonces no realizaron su fuerza. Los principios y máximas políticas emitidos en ese momento no han dejado de actuar. Las 
ideas sobre el equilibrio de los poderes fueron entonces introducidas y generalizadas, y todavía tienen influencia en los consejos de la naciones". ${ }^{24}$

Europa se arma entonces como un Estado único, íntimamente conectado e interdependiente, cuyos rasgos comunes pueden ser dibujados. $\mathrm{Al}$ mismo tiempo, sin embargo, la variedad de los caracteres nacionales aparece como otra característica europea y de sus distintos Estados:

\begin{abstract}
"Mientras esas instituciones y realidades, que acabo de mencionar, hicieron que los pueblos de Europa se parecieran unos a otros, y los han conducido de la barbarie a la fineza por el mismo sendero, y casi por las mismas etapas, otras circunstancias han creado diferencias en sus regímenes políticos, y dieron lugar a tipos de gobierno específicos, que han producido una gran variedad de temperamentos y genios nacionales”. 25
\end{abstract}

La introducción, titulada A View of the Progress of Civil Society in Europe, recorre los pasos que llevaron a la centralización de los poderes en los Estados europeos hasta la creación de Estados nacionales, durante el período comprendido entre la caída del Imperio romano y la llegada de Carlos V al escenario europeo. ¿Cómo se formó la sociedad civil en Europa? ¿Qué diferencia a Europa del resto del mundo? ¿Cuál es el resultado de haber pasado del desorden y de la barbarie, consecutivos a la caída del Imperio romano, hasta llegar al orden estable de la modernidad? Entre las causas de esta "revolución", Robertson pone el énfasis en la creación del comercio a consecuencia de las Cruzadas, la difusión del cristianismo, el espíritu caballeresco, la superación del pluralismo jurídico. Esos habrían sido los procesos civilizadores que actuaron en los usos y costumbres, difundieron humanidad, cortesía, justicia, honor y corrección como valores universales,

24 ROBERTSON, William, The History of the Reign of the Emperor Charles V. With a View of the Progress of Civil Society in Europe from the Subversion of the Roman Empire to the Beginning of the Sixteenth Century, Londres, W. Strahan, 1769, Preface, pp. x-xi. "The great events which happened then have not hitherto spent their force. The political principles and maxims, then established, still continue to operate. The ideas concerning the balance of power, then introduced or rendered general, still influence the councils of nations".

25Ibid., p. 123. "While these institutions and occurrences, which I have mentioned, formed the people of Europe to resemble each other, and conducted them from barbarism to refinement, in the same path, and with almost equal steps, there were other circumstances which occasioned a difference in their political establishments, and gave rise to those peculiar modes of government, which have produced such variety in the character and genius of nations". Sobre el papel central de Robertson en la Ilustración escocesa: SHER, Richard B., Church and University in the Scottish Enlightenment: The Moderate Literati of Edinburgh, Princeton, Princeton University Press, 1985; sobre las cuestiones de la diversidad humana: SEBASTIANI, Silvia, The Scottish Enlightenment. Race, Gender and the Limits of Progress, Nueva York, Palgrave, 2013. 
defendieron la castidad y el sacramento del matrimonio, moderaron los ardores bélicos. Pero sobre todo esos procesos pesaron de forma notable en el modo de concebir Europa en relación con los pueblos no europeos, es decir en el papel de las mujeres. La filosofía europea de la historia de los ilustrados introduce a la mujer en el relato histórico, como rasgo definitorio de la europeidad.

Los ilustrados, en particular franceses y escoceses, expresan la idea de que la mujer era mejor tratada en la Europa moderna y civilizada que en las sociedades de la Antigüedad, y que en las sociedades salvajes y bárbaras modernas en África, Asia y América. En esas sociedades, el imperativo de luchar para sobrevivir en contextos hostiles condenaba a las mujeres, físicamente más débiles que los hombres, a padecer una opresión total. Al haber afianzado la seguridad y la estabilidad en los modos de hacerse con la subsistencia y al haber reforzado los progresos de las artes, los valores femeninos ganan peso poco a poco, y la mujer acaba desempeñando un papel cada vez más digno y central. El propio proceso de civilización no es, en esa perspectiva, sino un proceso de feminización. ${ }^{26} \mathrm{El}$ Essai sur le caractère, les mours et l'esprit des femmes (1772) de Antoine-Léonard Thomas y el Origin of the Distinction of Ranks (1771) de John Millar desarrollan ese punto de vista. Ambos evalúan la relación salvaje / civilizado en función del modo de tratar a las mujeres, y marcan una ruptura clara entre Europa y el resto del mundo. Sin embargo, el discurso de la Ilustración sobre las mujeres, incluyendo a las europeas, no consigue asumir una perspectiva universalista. Si bien una mejor situación de las mujeres era indicio de progreso, al mismo tiempo, un exceso de feminidad podía ser entendido como señal de corrupción y decadencia.

\section{Derechos del hombre y libertad: las contradicciones del universalismo europeo}

El mismo problema de inclusión / exclusión afectaba la esfera jurídica y estaba en el centro del tema de los derechos del hombre que las revoluciones americana y francesa habían codificado. El iusnaturalismo de Locke había forjado el idioma

\footnotetext{
26 TOMASELLI, Sylvana, "The Enlightenment Debate on Women”, History Workshop Journal, 20, 1985, pp. 101-124; GUERCI, Luciano, La sposa obbediente: donna e matrimonio nella discussione dell'Italia del Settecento, Turín, Tirrenia Stampatori, 1988; KNOTT, Sarah; TAYLOR, Barbara (ed.), Women, Gender and Enlightenment, Londres-Nueva York, Palgrave-Macmillan, 2005; TAYLOR, Barbara, "Enlightenment and the Uses of Woman", History Workshop Journal, vol. 74, 2012, pp. 7987.
} 
teórico fundamental, presentando tensiones perdurables. Según Locke, los seres humanos son por naturaleza titulares de derechos fundamentales, basados en el par libertad / propiedad. La propiedad no es sinónimo de posesión u ocupación de un espacio vacío. Es, antes bien, el producto de la auto-disciplina ("property in his own person"), del "labour" y de la "industry", mediante los cuales el individuo se hace con los bienes. Si "in the beginning all the world was America", Europa había progresado gracias a la invención de la moneda, que había hecho posible la acumulación y el comercio: la propiedad cobra la forma de aprovechamiento intensivo de los recursos culturales, hace posible la multiplicación de los bienes y el enriquecimiento individual y colectivo. Es lo que hace al pobre trabajador inglés más rico que cualquier rey de la América salvaje, según Locke. Los indios americanos no habían conseguido pasar de la propiedad improductiva a la propiedad productiva, o de la economía de subsistencia a la economía mercantil, es decir de la barbarie a la civilización, señal de ruptura radical. El mismo derecho fundamental de la libertad - propiedad, reduce la distancia entre unos y otros, pero también la reintroduce. Los salvajes de América no disponen de aquella industria capaz de convertir la tierra en productiva, lo que les priva de poder ser considerados como sus legítimos propietarios. América, por haber sido mantenida inculta por sus habitantes, es considerada como tierra de nadie y por consiguiente disponible para quien se proponga sacar fruto de ella. El mismo derecho de la libertad - propiedad que en Europa garantiza una autonomía sólida de los sujetos es instrumento de la expropiación de los salvajes. ${ }^{27}$

Las primeras versiones modernas de los derechos del hombre están íntimamente vinculadas con la experiencia colonial y hacen compatible la tesis de la igualdad fundamental de los seres humanos con la teoría de las diferencias entre "civilizados" y "salvajes", y con la dominación de los primeros sobre los segundos. Al mismo tiempo, el propio Locke define como "natural" la subordinación de la mujer al hombre, basándose en la idea que ella es "naturalmente" menos capaz de disciplinarse y convertirse en propietaria de sí misma: he aquí el supuesto

\footnotetext{
${ }^{27}$ ARNEIL, Barbara, John Locke and America. The Defense of English Colonialism, Clarendon Press, Oxford 1996; TULLY, James, "Aboriginal Property and Western Theory: Recovering a Middle Ground”, David ARMITAGE (ed.), Theories of Empire 1450-180o, Aldershot, Ashgate, 1998, pp. 345372; COSTA, Pietro, Civitas: storia della cittadinanza in Europa, 4 vols., Bari, Laterza, 2003, vol. 1, pp. 285 ss; ARMITAGE, David, "John Locke, Carolina, and the Two Treatises of Government", Political Theory, Vol. 32, No. 5, 2004, pp. 602-627.
} 
indiscutible (natural y no político) del contrato social. ${ }^{28}$ Salvajes, mujeres y esclavos permanecieron al margen de la ciudadanía, y no es casualidad que las voces que se levantaron a favor de la defensa de los derechos de la mujer se hayan mezclado con el movimiento a favor de la abolición de la esclavitud, desde Mary Wollstonecraft hasta los movimientos abolicionistas americanos de la primera mitad del siglo XIX.29 La Scienza della legislazione (1780-87) de Gaetano Filangieri define (como John Locke) el vínculo libertad - propiedad como la viga que sostiene los derechos inalienables. Pero les confiere un significado igualitario. Según Filangieri, existe una razón universal que hace que el habitante de Tahití comparta con el filósofo el mismo principio de justicia y propiedad. El derecho de resistencia de los colonizados proviene de allí con plena justificación y se convierte en principio de la primera revolución moderna. Sin embargo la ambigüedad permanece, como muestran los recién nacidos Estados Unidos cuyo doloroso parto nos deja otra herencia: la cuestión de la "whiteness" (blancura). ¿Cómo asegurar la limpieza de sangre de la "raza blanca" frente a la emancipación de los esclavos? ¿Cómo impedir la contaminación? El primer Estado moderno americano sustituye a la europeidad por el color de la piel: la igualdad civil de los negros no será plenamente reconocida en la primera colonia que se levantó contra Europa, hasta 1964.

De lo anterior se desprende que el paulatino tránsito del concepto de Cristiandad al de Europa es fruto de la confrontación que han vivido los europeos con aquellos pueblos, territorios y culturas a los que supieron o intentaron dominar, al menos desde el siglo XV. La cristiandad triunfó, pero no sin melancolía. Triunfó de forma pírrica. Adentro resistía la aberración judía: aberrante judaísmo porque aquellos mismos que habían dado a luz al Salvador y a sus apóstoles eran aquellos que se negaban, pertinaces, a admitir que aquel hijo suyo fuera un mesías. Afuera los europeos tuvieron que reconocer cierta superioridad de sus adversarios, el caballero Saladino, el sultán otomano, el emperador de China, y hasta de sus vencidos como muestran el asombro de Cortés delante de Tenochtitlán. Aplastar y conocer; dominar

28 PATEMAN, Carole, The Sexual Contract, Stanford, Stanford University Press, 1988.

29 FONER, Eric, The Story of American Freedom, Nueva York, W.W. Norton \& Company, 1998. 
y describir; eliminar e inventariar a escala global: esos son los pasos de unas andanzas sin igual en la historia conocida. Los europeos no dejaron nunca de inventariar sus fracturas internas, a la par que reflejaban su propia existencia en el espejo de mundos ajenos. Ese doble movimiento es el que, con el giro de la Ilustración, hizo que la noción teológica de cristiandad dejara paso a la idea de Europa. Una idea y una realidad todavía inacabadas. ${ }^{30}$

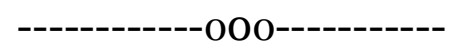

\section{Referencias bibliográficas}

ARMITAGE, David, "John Locke, Carolina, and the Two Treatises of Government", Political Theory, Vol. 32, No. 5, 2004, pp. 602-627.

ARNEIL, Barbara, John Locke and America. The Defense of English Colonialism, Oxford, Clarendon Press, 1996.

BAYLY, Christopher A., Empire and Information. Intelligence Gathering and Social Communication in India, 1780 1870, Cambridge, Cambridge University Press, 1997.

BEREND, Nora, At the gate of Christendom: Jews, Muslims, and "pagans" in medieval Hungary, c. 1000 - c. 1300 , Cambridge-Nueva York, Cambridge University Press, 2001.

BOULLE, Pierre H., Race et esclavage dans la France de l'Ancien Régime, Paris, Perrin, 2007.

BREWER, John, The Sinews of Power: War, Money, and the English State, 16881783, Nueva York, Knopf, 1989.

BUFFON, G.L.L., Des époques de la nature (1778), en Euvres, ed. S. Schmitt, Paris, 2007.

CHABOD, Federico, Storia dellidea di Europa, Roma-Bari, Laterza, 1989.

COLLEY, Linda, Britons: Forging the Nation, 1707-1837, New Haven, Yale University Press, 1992.

COSTA, Pietro, Civitas: storia della cittadinanza in Europa, Bari, Laterza, 2003, vol. 1.

DAKHLIA, Jocelyne; VINCENT, Bernard (ed.), Les musulmans dans l'histoire de l'Europe, vol. I, Une intégration invisible, Paris, Albin Michel, 2011.

${ }^{30}$ Queremos agradecer a Rafael Mandressi por su relectura atenta y sus comentarios agudos. 
DUCHET, Michèle, Anthropologie et histoire au siècle des Lumières (1971), Postface de Claude Blanckaert, Paris, Albin Michel, 1995.

FEBVRE, Lucien, "Civilisation: évolution d'un mot et d'un groupe d'idées" (1930), en Pour une histoire à part entière, Paris, SEVPEN, 1962, pp. 481-528.

FONER, Eric, The Story of American Freedom, Nueva York, W.W. Norton \& Company, 1998.

FORSTER, Georg, Ansichten vom Niederrhein, von Brabant, Flandern, Holland, England und Frankreich, im April, Mai und Junius 1790, (1791), ed. G. Steiner, Berlín, 1958.

GLIOZZI, Giuliano, Adamo e il Nuovo Mondo. La nascita dell'antropologia come ideologia coloniale dalle genealogie bibliche alle teorie razziali (1500-1700), Florencia, La Nuova Italia, 1977.

GUERCI, Luciano, La sposa obbediente: donna e matrimonio nella discussione dell'Italia del Settecento, Turín, Tirrenia Stampatori, 1988.

HAZARD, Paul, La crise de la conscience européenne, Paris, Boivin, 1935.

HOQUET, Thierry, "La nouveauté du Nouveau Monde du point de vue de l'histoire naturelle", G. ABBATTISTA; R. MINUTI (ed.), Le problème de l'altérité dans la culture européenne. Anthropologie, politique et religion aux XVIIIe et XIXe siècles, Nápoles, Bibliopolis, 2006, pp. 129-158.

KAEGI, Werner, "Voltaire e la disgregazione della concezione cristiana della storia", en Meditazioni storiche, Bari, Laterza, 1960, pp. 216-238.

KNOTT, Sarah; TAYLOR, Barbara (ed.), Women, Gender and Enlightenment, Londres-Nueva York, Palgrave-Macmillan, 2005.

LATOUR, Bruno, "Ces réseaux que la raison ignore: laboratoires, bibliothèques, collections", M. BARATIN; C. JACOB (ed.), Le Pouvoir des bibliothèques. Le Pouvoir des livres en Occident, Paris, Albin Michel, 1996, pp. 23-46.

LILTI, Antoine, "L'impossible histoire globale. Parcours de la "civilisation", Antoine LILTI; Sabina LORIGA; Jean-Frédéric SCHAUB; Silvia SEBASTIANI (ed.), L'expérience historiographique. Autour de Jacques Revel, Paris, Editions de l'EHESS (Enquêtes n. 12), 2016, pp. 181-200.

LILTI, Antoine, "La civilisation est-elle européenne ? Ecrire l'histoire de l'Europe au XVIIIe siècle”, A. LILTI; Céline SPECTOR (ed.), Penser à l'Europe au 18 siècle, Oxford, Voltaire Fondation, 2014, pp. 139-166.

MEEK, Ronald L., Social Science and Ignoble Savage, Cambridge, Cambridge University Press, 1976.

PAGDEN, Anthony, “The 'Defence of Civilization' in Eighteenth-Century Social Theory”, History of the Human Sciences, 1, 1988, pp. 33-45.

PATEMAN, Carole, The Sexual Contract, Stanford, Stanford University Press, 1988.

PHILLIPS, Mark Salber, Society and Sentiment. Genres of Historical Writing in Britain, 1740-1820, Princeton, Princeton University Press, 2000.

PROSPERI, Adriano, Il seme dell'intolleranza. Ebrei, eretici, selvaggi, Granada 1492, Roma-Bari, Laterza, 2011.

ROBERTSON, William, The History of the Reign of the Emperor Charles $V$. With a 
View of the Progress of Civil Society in Europe from the Subversion of the Roman Empire to the Beginning of the Sixteenth Century, Londres, W. Strahan, 1769.

SCHAUB, Jean-Frédéric, "«Nous, les barbares»: expansion européenne et découverte de la fragilité intérieure", Patrick BOUCHERON (ed.), Histoire du monde au $X V^{e}$ siècle, Paris, Fayard, 2009, pp. 813-829.

SEBASTIANI, Silvia, The Scottish Enlightenment. Race, Gender and the Limits of Progress, Nueva York, Palgrave, 2013.

SHER, Richard B., The Enlightenment and the Book. Scottish Authors and their Publishers in Eighteenth-Century Britain, Irlanda y América, ChicagoLondres, University of Chicago Press, 2006.

SHER, Richard B., Church and University in the Scottish Enlightenment: The Moderate Literati of Edinburgh, Princeton, Princeton University Press, 1985.

STAROBINSKI, Jean, "Le mot civilisation", in Le remède dans le mal : Critique et légitimation de l'artifice à l'âge des Lumières, Paris, Gallimard, 1989, pp. 1159.

TAYLOR, Barbara, "Enlightenment and the Uses of Woman", History Workshop Journal, vol. 74, 2012, pp. 79-87.

TOMASELLI, Sylvana, “The Enlightenment Debate on Women", History Workshop Journal, 20, 1985, pp. 101-124.

TULLY, James, "Aboriginal Property and Western Theory: Recovering a Middle Ground", David ARMITAGE (ed.), Theories of Empire 1450-180o, Aldershot, Ashgate, 1998, pp. 345-372.

VERGA, Marcello, Storie d'Europa, secoli XVIII-XXI, Roma, Carocci, 2004.

WESSELING, Henk, Europa's kolonial eeuw. De kolonial rijken in de negentiende eeuw, 1815-1919, Amsterdam, Bert Bakker, 2003.

WOLFF, Larry, "Discovering Cultural Perspective. The Intellectual History of Anthropological Thought in the Age of Enlightenment", Larry WOLFF; Marco CIPOLLONI (ed.), The Anthropology of the Enlightenment, Stanford, Stanford University Press, 2007, pp. 3-32.

WOLFF, Larry, Inventing Eastern Europe: The Map of Civilization on the Mind of the Enlightenment, Palo Alto, Stanford University Press, 1994. 